
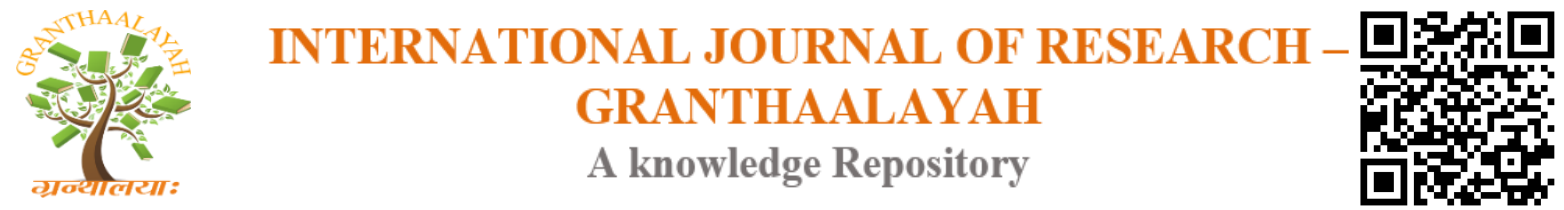

Management

\title{
THE EFFECT OF CONSUMER ATTITUDE ON PURCHASING INTENTION FOR ORGANIC PRODUCTS
}

\author{
Dr. Ashutosh Sandhe ${ }^{* 1}$ \\ ${ }^{* 1}$ Commerce \& Management Department, Team Lease Skills University, India
}

\begin{abstract}
This research paper examines the effect of consumer attitude on purchasing intention towards organic or eco-friendly paints. Attitude was measured through tri-component model of attitude formation. Data was collected from 300 respondents in the city of Vadodara, Gujarat, India. Respondents were administered a structured questionnaire containing statements measuring attitude in terms of cognitive, affective and conative factors. Responses were collected in the form of a five point likert scale ranging from "strongly agree" to "strongly disagree". Consumer attitude and purchasing intention was found to be moderately favorable. The research highlighted the fact that consumers are not aware about the availability of such a product in the market. This is an important finding from the view point of marketing research.
\end{abstract}

Keywords: Attitude; Purchasing Intention; Cognitive; Affective; Conative; Organic Paints.

Cite This Article: Dr. Ashutosh Sandhe. (2019). "THE EFFECT OF CONSUMER ATTITUDE ON PURCHASING INTENTION FOR ORGANIC PRODUCTS." International Journal of Research - Granthaalayah, 7(2), 1-9. https://doi.org/10.29121/granthaalayah.v7.i2.2019.987.

\section{Introduction}

It is a well-known fact that any paint whether for interiors of a house or exteriors, for automobiles or industry, contains lot of harmful substances which are called volatile organic compounds (VOC). These substances not only cause a harm to the health of individuals and animals, they pose a serious threat to the environment.

According to some recent studies, in conventional paints, more than ten thousand chemicals are used. These chemicals are likely to lead to health issues in the long run like allergies, headaches, reactions, etc. Some of the elements found in the paint like formaldehyde and benzene are carcinogenic while some other chemicals contain heavy metals which are toxic to humans and the ecosystem.

With these risks to the society as well as ecology, scientists have developed paints which contain non-toxic elements. These paints are non-toxic with little or no Volatile Organic Compounds (VOC). They have no smell and come in a variety of colour. They are also suitable to those people 
who are allergic or sensitive to the conventional paints. As compared to the conventional paints, these eco-friendly or organic paints contain less than 250 chemicals out which studies have hinted that more than 98 percent of these chemicals are naturally obtained from plants and minerals. These materials have also been found to be renewable and less toxic ${ }^{1}$.

The purpose of this research was to study and analyse the attitude of consumers in the city of Vadodara, India towards these eco-friendly or organic paints. After examining the consumer attitude of respondents, the impact of attitude on purchasing intention was also studied. In order to study attitude the Tri-component model of attitude formation was used. As Schiffman has defined, "Attitudes are an expression of inner feelings that reflect whether a person is favorably or unfavorably predisposed to some "object" (e.g., a brand, a service, or a retail establishment)," and "Attitude formation, in turn, is the process by which individuals form feelings or opinions toward other people, products, ideas, activities, and other objects in their environment". ${ }^{2}$

Attitude has been defined by Kanuk and Schifmann as "a learned predisposition to behave in a consistently favorable or unfavorable way based on feelings and opinions that result from an evaluation of knowledge about the object". ${ }^{3}$

The tri-component model suggests that attitude is formed as a result of interaction of three components which are named as the cognitive component, affective component and conative component.

\section{Cognitive Component}

Cognitive component comprises the knowledge and perceptions a person holds about the attitude object (product/service). They are acquired from their direct experience with the attitude object as well as information sources.

\section{Affective Component}

This component is about consumers' emotions and feelings about the attitude object. They are also called evaluations as they give insight about the overall assessment of the attitude object as being "good" or "bad" or as "favourable" or "unfavourable".

\section{Conative Component}

This component highlights the probability or likelihood that person will behave in a particular way with regard to the attitude object.

\section{Literature Review}

Online private label products seem to be a promising and profitable deal for the Indian online retailers. The purpose of this paper was to understand the consumers' attitude and buying behaviour towards online private label brands. For this purpose, we empirically tested a model comprising of variables such as cognitive, affective, behavioural, purchase intention, and actual buying behaviour. Data were gathered by using a schedule. A sample of 400 respondents was gathered,

\footnotetext{
${ }^{1}$ http://www.ecoindia.com/products/paints.html

${ }^{2}$ Schiffman,L.G.; and Kanuk,L.L.; Consumer Behaviour, Prentice Hall, India,8th Edition, 2004.

${ }^{3}$ Schiffman,L.G.; and Kanuk,L.L.; Consumer Behaviour, Prentice Hall, India,8th Edition, 2004.
} 
and the hypotheses were tested by performing structural equation modelling. The findings highlighted that the cognitive, affective, and behavioural factors of attitude influenced each other strongly as well as the purchase intention. In addition, the results obtained revealed that purchase intention led to the buying of online private label brands. It is expected that the findings of this study will enable the marketers of online private label brands to be more informed about the consumers' attitude formation process. Furthermore, it will help them to understand the areas related to private label brands, which need their attention. ${ }^{4}$

Sandhe Ashutosh and Joshi Ashwini (2017), analysed the attitude of people of Vadodara towards organic food products. Attitude was studied by application of the Tri-component Model where three major components of attitude i.e. cognition, affection and conation or purchasing intention were measured and from that the overall attitude was found. It was observed that the overall attitude for organic food products was favourable and that there was strong positive correlation between all the three components and attitude. Further, reasons for preference of organic food products were also studied along with problems faced in procurement of these products in Vadodara. "Organic food products are good for health" was found to be the most prominent reason for preference of these products and these products are not easily available everywhere was found as a major problem faced in procurement in Vadodara. ${ }^{5}$

Maichum. K et al (2017) carried out their research in Thailand to investigate the factors that influence the purchasing intention for green products of young Thai consumers. The results they obtained suggested that environmental consciousness, environmental knowledge and environmental attitude have significant positive influences on the purchasing intention for green products. Based on the results, they observed that environmental attitude had high significant effect on the purchasing intention of consumers. ${ }^{6}$

Dipti Barge et al. (2015) observed in their research in 2015 that people find the price of environmental friendly products to be higher than that of the traditional ones and hence there is a lack of purchasing intention for them. Not only a lack of purchasing intention was observed, there was a lack of positive attitude towards these products even though they are aware of these products. $^{7}$

Naresh Kanwar (2014) in his research on environment friendly products found that purchasing intention of people living in high income areas of the city was high as compared to those living in low income areas of the same city. Thus, he observed that locality and income earning capacity of the consumer has a bearing on the purchasing intention for environment friendly products. ${ }^{8}$

\footnotetext{
${ }^{4}$ Ruchita Pangriya, M. Rupesh Kumar, (2018), A Study of Consumers' Attitude Towards Online Private Label Brands Using the Tri - Component Model, Indian Journal of Marketing, Vol.48(5).

${ }^{5}$ Sandhe Ashutosh, Joshi, Ashwini, (2017), Consumers' Attitude towards Organic Food Products in Vadodara - An Exploratory Study, Pacific Business Review International, Vol.10 (01), PP.32-40.

${ }^{6}$ Kamonthip Maichum, Surakiat Parichatnon, and Ke-Chung Peng, (2017), Factors Affecting on Purchase Intention towards Green Products: A Case Study of Young Consumers in Thailand, International Journal of Social Science and Humanity, Vol.7(5), PP.330-335

${ }^{7}$ Barge, Dipti, K. More, Dinkar, Bhola, Sarang. (2015). Eco Friendly Products Attitude towards Pricing. SSRN Electronic Journal. 10.2139/ssrn.2589415.

${ }^{8}$ Kanwar Naresh, (2014), Green Marketing and the Indian Consumer, International Journal of Business and Management Invention, Vol.3 (3), PP.58-62.
} 
Chia-Lin Hsu and Mu-Chen Chen, (2014), examined the influence of regulatory fit on consumer attitude and purchasing intention for organic food in Taiwan. The research also highlighted the moderating role of consumer characteristics. They found that the occurrence of a regulatory fit results into a positive and higher purchasing intention for organic foods. The research also concluded that attitude and purchasing intention are moderated by the characteristics of the consumers. The characteristics highlighted were like trust propensity and self-confidence. ${ }^{9}$

In their research, Preeti Pillai and Indra Meghrajani, (2013) studied the attitude and purchasing intention of people with differing demographic background towards purchase of environment friendly products in the city of Ahmedabad. They found that for each demographic characteristic, the awareness for eco-friendly products was same. There was some dependency on age, occupation and education for considering eco-friendly products. Finally, the major sources of information were found to be television and newspapers. ${ }^{10}$

Jamaliah Mohd. Yusof et al (2013) analysed the purchasing intention for environment friendly automobile by examining the relationship between consumers' environment responsibility feeling, values, knowledge, perceptions of environmental advertisement and environment-friendly automobile. They found that environment knowledge has no significant influence on perception about the eco-friendly automobile. On the other side, environment responsibility feeling and values have significant influence on perception of environmental advertisement and product. Another conclusion they drew was that perception of environmental advertisement has no impact on purchasing intention, whereas perception of environment friendly automobile can affect purchasing intention. ${ }^{11}$

\section{Research Methodology}

This research can be categorized as a descriptive and exploratory research as it tries to understand the consumer attitude towards organic products in Vadodara. For the purpose of this research a sample size of 300 was considered appropriate. Data was collected through probabilistic random sampling from respondents residing in the city of Vadodara. Approximately 338 questionnaires were administered out which valid forms were considered for analysis.

The data for this research was collected in the form of a structured questionnaire. The questionnaire was divided into 3 parts. First part of the questionnaire dealt with attitude formation of the respondents. The second part of the questionnaire had questions measuring purchasing intention and last part comprised demographic profile of the respondents. The first two parts of the questionnaire contained questions in the form of statements for which agreement was sought from respondents. The questions were based on a five point likert scale where a score of 5 was assigned

\footnotetext{
${ }^{9}$ Chia-Lin Hsu, Mu-Chen Chen, (2014), Explaining consumer attitudes and purchase intentions toward organic food: Contributions from regulatory fit and consumer characteristics, Food Quality and Preference - Elsevier, Vol.35, PP.613

${ }^{10}$ Preeti Pillai, Indra Meghrajani, (2013), Consumer Attitude Towards Eco-Friendly Goods - A Study Of Electronic Products In Ahmedabad City, International Journal of Engineering Research \& Technology (IJERT), Vol.2(7), PP.1124-1127

11 Jamaliah Mohd. Yusof, Gurmit Kaur Bariam Singh, Rashidah Abdul Razak, (2013), Purchase Intention of Environment-Friendly Automobile, Procedia - Social and Behavioral Sciences, PP.400-410
} 
to "Strongly Agree" and 1 to "Strongly Disagree". As mentioned earlier, attitude was measured on the basis of its three components i.e. cognition, affection and conation.

Before further analyzing the data, it was tested for reliability and following results were obtained through Cronbach Alpha, the famously accepted test of inter-item consistency reliability (Sekaran and Bougie (2010) ${ }^{12}$. The alpha values were found to be significant since all the values obtained were above the statistical value of 0.60 . Based on the values obtained for Cronbach Alpha, further analysis of the data collected and tabulated was undertaken.

Table 1: Reliability Analysis

\begin{tabular}{|l|l|}
\hline Factor & Alpha \\
\hline Cognition & 0.692 \\
\hline Affection & 0.882 \\
\hline Conation & 0.751 \\
\hline Overall Attitude & 0.87 \\
\hline Purchasing Intention & 0.911 \\
\hline
\end{tabular}

\section{Objectives}

The research was carried out to achieve the following objectives-

- To study the overall attitude of respondents towards organic paints in Vadodara.

- To study the overall purchasing intention for organic paints in Vadodara.

- To study the impact of attitude on purchasing intention for organic paints in Vadodara.

\section{Hypotheses}

H1: There is lack of attitude formation for organic paints in Vadodara

$\mathrm{H} 2$ : There is lack of significant purchasing intention for organic paints in Vadodara

H3: There is lack of significant impact of consumer attitude on purchasing intention for organic paints in Vadodara.

\section{Data Analysis}

Table 2 below gives an overview of the demographic profile of respondents surveyed in this research. As can be seen, majority of the respondents were in the age group of up to 40 years $(81.33 \%)$. With respect to income groups, majority of the respondents were in the income group between 3 lakhs to above 6 lakhs $(62.33 \%)$. In terms of the Indian counting system the number 1 lakh is equal to a 100 thousands in international terms. With reference to occupation, 83.33\% respondents were working as service people or had a business of their own or were involved in some profession like a doctor or lawyer or an accountant, etc.

12 Mohd Hamran Mohamad, Zulkiflee Daud, Khulida Kirana Yahya, (2014), Prediction of Transformational Leadership on Employees' Good Governance in Malaysian Local Government Authorities: A Pilot Study, International Journal of Management Research and Review, Vol.4 (2), PP.163-171. 
Table 2: Demographic Characteristics of the Respondents

\begin{tabular}{|c|c|c|c|c|c|c|c|}
\hline Feature & & $\mathbf{N}$ & $\%$ & Feature & & $\mathbf{N}$ & $\%$ \\
\hline \multirow[t]{4}{*}{ Age } & $20-30$ & 136 & 45.33 & \multirow[t]{5}{*}{ Income } & $<1.5 \mathrm{Lac}$ & 48 & 16.00 \\
\hline & $31-40$ & 78 & 26.00 & & $1.5-3.00$ & 65 & 21.67 \\
\hline & $41-50$ & 44 & 14.67 & & $3.01-4.5$ & 58 & 19.33 \\
\hline & Above 50 & 42 & 14.00 & & $4.51-6.00$ & 63 & 21.00 \\
\hline \multicolumn{2}{|l|}{ Total } & 300 & 100.00 & & Above 6 & 66 & 22.00 \\
\hline \multirow[t]{2}{*}{ Gender } & Male & 169 & 56.33 & \multicolumn{2}{|l|}{ Total } & 300 & 100.00 \\
\hline & Female & 131 & 43.67 & \multirow[t]{2}{*}{ Family Size } & $1-4$ & 176 & 58.67 \\
\hline \multicolumn{2}{|l|}{ Total } & 300 & 100.00 & & $5-7$ & 88 & 29.33 \\
\hline \multirow[t]{4}{*}{ Education } & Under Graduate & 39 & 13.00 & & Above 7 & 36 & 12.00 \\
\hline & Graduate & 92 & 30.67 & \multicolumn{2}{|l|}{ Total } & 300 & 100.00 \\
\hline & Post Graduate & 128 & 42.67 & \multirow[t]{2}{*}{ Family Type } & Nuclear & 188 & 62.67 \\
\hline & Professional & 41 & 13.67 & & Joint & 112 & 37.33 \\
\hline \multicolumn{2}{|l|}{ Total } & 300 & 100.00 & \multicolumn{2}{|l|}{ Total } & 300 & 100.00 \\
\hline \multirow[t]{5}{*}{ Occupation } & Service & 113 & 37.67 & \multirow[t]{2}{*}{ Marital Status } & Married & 163 & 54.33 \\
\hline & Business & 79 & 26.33 & & Unmarried & 137 & 45.67 \\
\hline & Professional & 58 & 19.33 & \multicolumn{2}{|l|}{ Total } & 300 & 100.00 \\
\hline & Homemaker & 18 & 6.00 & & & & \\
\hline & Others & 32 & 10.67 & & & & \\
\hline \multicolumn{2}{|l|}{ Total } & 300 & 100.00 & & & & \\
\hline
\end{tabular}

H1: There is lack of attitude formation for organic paints in Vadodara

$\mathrm{H} 2$ : There is lack of significant purchasing intention for organic paints in Vadodara

The first and primary objective of this research was to test the attitude formation levels of respondents for organic paints in Vadodara. For this, attitude formation was studied from the point of view of its factors which were cognitive, affective and conative as discussed earlier. Mean analysis was carried out to study and analyse consumer attitude and following results were obtained.

Table 3: Mean Analysis for Attitude and Purchasing Intention for Organic Paints.

\begin{tabular}{|l|l|l|l|l|l|l|}
\hline Factor & Mean & s.d. & t-value & p-value & Chi-Square & p-value \\
\hline Cognition & 3.87 & 0.561 & 81.050 & 0.000 & 28.174 & 0.000 \\
\hline Affection & 3.46 & 0.460 & 88.544 & 0.000 & 26.348 & 0.000 \\
\hline Conation & 3.87 & 0.629 & 72.358 & 0.000 & 64.435 & 0.000 \\
\hline Overall Attitude & 3.73 & 0.467 & 94.049 & 0.000 & 39.391 & 0.000 \\
\hline Purchasing Intention & 3.75 & 0.484 & 96.011 & 0.000 & 95.739 & 0.000 \\
\hline
\end{tabular}

As the table suggests, the overall attitude for organic paints was found to be favourable in Vadodara (Mean =3.73). Along with attitude, purchasing intention was also found to be positive $($ Mean $=3.75)$. Further analysis of the data revealed that all the factors leading to consumer attitude formation also had mean values on the positive side. Of the three components of attitude, the component 'Affection' and 'Conation' had same mean values (Mean =3.87). In order to test the validity and general applicability of these results, $t$-test and chi-square test was carried out and it 
was observed that the results were highly significant. The significance value for both the test was less than the confidence value of 0.05. Thus, the null hypothesis was rejected and alternate hypothesis was accepted. Apart from the statistical observation, it was found that all the mean values were just above the median value of 3 . All the mean values were less than 4 on a five point scale. This indicated that though there was favourable attitude and positive purchasing intention for organic paints in Vadodara, it was not very strong. The values ranged between 3.46 and 3.87 suggesting just above average opinion for organic paints in Vadodara. The reason for this was the overall lack of awareness. During the study, we found lot of respondents who were not aware about organic or eco-friendly paints being available in market.

The same results suggested that purchasing intention was positive for organic paints in Vadodara. Thus, the second hypothesis was also rejected.

H3: There is lack of significant impact of consumer attitude on purchasing intention for organic paints in Vadodara.

Table 4: Paired Sample t-test for Attitude and Purchasing Intention

\begin{tabular}{|l|l|l|l|l|}
\hline Variables & Correlation & sig. & t-value & sig. \\
\hline PI \& Att. & 0.617 & 0.000 & 6.074 & 0.000 \\
\hline Cog. - Att. & 0.869 & 0.000 & 5.588 & 0.000 \\
\hline Aff. - Att. & 0.782 & 0.000 & 10.483 & 0.000 \\
\hline Con. - Att. & 0.879 & 0.000 & 5.255 & 0.000 \\
\hline
\end{tabular}

(PI- Purchasing Intention, Att. - Attitude, Cog. - Cognition, Aff.-Affection, Con.-Conation)

Paired sample t-test was carried out to study the impact of consumer attitude on purchasing intention for organic paints in Vadodara. Table 4 shows the results obtained. It was found that there was moderate to strong positive correlation between attitude and purchasing intention $(\mathrm{r}=0.617, \mathrm{p}=0.000)$. The results also indicated a strong positive correlation between components of attitude and attitude itself. Not only that, all the components of attitude formation had a strong and positive relation with purchasing intention. Hence, the hypothesis was rejected and alternate hypothesis was accepted.

Table 5: Correlation Analysis

\begin{tabular}{|l|l|l|l|l|l|}
\hline & Cog. & Aff. & Con. & Att. & PI. \\
\hline Cog. & 1 & 0.548 & 0.644 & 0.870 & 0.511 \\
\hline Sig. & & 0.000 & 0.000 & 0.000 & 0.000 \\
\hline Aff. & 0.548 & 1 & 0.518 & 0.781 & 0.781 \\
\hline Sig. & 0.000 & & 0.000 & 0.000 & 0.000 \\
\hline Con. & 0.644 & 0.518 & 1 & 0.878 & 0.605 \\
\hline Sig. & 0.000 & 0.000 & & 0.000 & 0.000 \\
\hline Att. & 0.870 & 0.781 & 0.878 & 1 & 0.617 \\
\hline Sig. & 0.000 & 0.000 & 0.000 & & 0.000 \\
\hline PI & 0.511 & 0.781 & 0.605 & 0.617 & 1 \\
\hline Sig. & 0.000 & 0.000 & 0.000 & 0.000 & \\
\hline
\end{tabular}

(Significance at 99\%, 2-tailed significance)

(Cog. - Cognition, Aff. - Affection, Con.- Conation, Att. - Attitude, PI- Purchasing Intention) 
The above table shows the relationship between attitude formation and purchasing intention for organic paints in Vadodara. As seen in the table, there is a positive relationship amongst all the variables. Consumer attitude and purchasing intention are strongly related with a coefficient of 0.617. All the values are in the range between 0.511 and 0.878 suggesting high correlation values for all the factors. All the values of correlation were found to be highly significant at $99 \%$ confidence levels.

\section{Findings}

This research highlighted some interesting facts about consumer behavior for organic paints in Vadodara. The overall attitude for these eco-friendly paints was found to be moderately favourable. Same was found for purchasing intention. The purchasing intention for these products was found to be moderately positive. However, it was also found during the survey and collection of primary data that a lot of respondents were unaware about the availability of these products in Vadodara. Thus, the implication for marketers for organic paints would be to create awareness about the availability of organic paints in the market. Even with limited awareness, the results were encouraging for the products and overall for the environment.

\section{Conclusion}

The research led to the conclusion that there is a good chance for the growth of organic paints or eco-friendly paints in India. The results obtained were encouraging. Further analysis could lead to further inferences in this regard.

\section{References}

[1] http://www.ecoindia.com/products/paints.html

[2] Barge, Dipti, K. More, Dinkar, Bhola, Sarang. (2015). Eco Friendly Products Attitude towards Pricing. SSRN Electronic Journal. 10.2139/ssrn.2589415.

[3] Chia-Lin Hsu, Mu-Chen Chen, (2014), Explaining consumer attitudes and purchase intentions toward organic food: Contributions from regulatory fit and consumer characteristics, Food Quality and Preference - Elsevier, Vol.35, PP.6-13

[4] Jamaliah Mohd. Yusof, Gurmit Kaur Bariam Singh, Rashidah Abdul Razak, (2013), Purchase Intention of Environment-Friendly Automobile, Procedia - Social and Behavioral Sciences, PP.400-410

[5] Kamonthip Maichum, Surakiat Parichatnon, and Ke-Chung Peng, (2017), Factors Affecting on Purchase Intention towards Green Products: A Case Study of Young Consumers in Thailand, International Journal of Social Science and Humanity, Vol.7(5), PP.330-335

[6] Kanwar Naresh, (2014), Green Marketing and the Indian Consumer, International Journal of Business and Management Invention, Vol.3 (3), PP.58-62.

[7] Mohd Hamran Mohamad, Zulkiflee Daud, Khulida Kirana Yahya, (2014), Prediction of Transformational Leadership on Employees' Good Governance in Malaysian Local Government Authorities: A Pilot Study, International Journal of Management Research and Review, Vol.4(2), PP.163-171.

[8] Preeti Pillai, Indra Meghrajani, (2013), Consumer Attitude Towards Eco-Friendly Goods - A Study Of Electronic Products In Ahmedabad City, International Journal of Engineering Research \& Technology (IJERT), Vol.2(7), PP.1124-1127 
[9] Ruchita Pangriya, M. Rupesh Kumar, (2018), A Study of Consumers' Attitude Towards Online Private Label Brands Using the Tri - Component Model, Indian Journal of Marketing, Vol.48(5).

[10] Sandhe Ashutosh, Joshi, Ashwini, (2017), Consumers' Attitude towards Organic Food Products in Vadodara - An Exploratory Study, Pacific Business Review International, Vol.10 (01), PP.32-40.

[11] Schiffman,L.G.; and Kanuk,L.L.; Consumer Behaviour, Prentice Hall, India,8th Edition, 2004.

\footnotetext{
*Corresponding author.

E-mail address: ashutoshsandhe@yahoo.com
} 